\title{
General Psychiatry Phenomenological analysis of maladaptive daydreaming associated with internet gaming addiction: a case report
}

Prerna Sharma (D), Ananya Mahapatra

To cite: Sharma P, Mahapatra A. Phenomenological analysis of maladaptive daydreaming associated with internet gaming addiction: a case report. General Psychiatry 2021;34:e100419. doi:10.1136/ gpsych-2020-100419

Received 02 October 2020 Revised 29 November 2020 Accepted 07 February 2021
Check for updates

(C) Author(s) (or their employer(s)) 2021. Re-use permitted under CC BY-NC. No commercial re-use. See rights and permissions. Published by BMJ.

Department of Psychiatry and Drug-de Addiction, Center fo Excellence in Mental Health, ABVIMS \& Dr. RML Hopsital, New Delhi, India

Correspondence to Dr Prerna Sharma; prernasharma02@gmail.com

\section{ABSTRACT}

Maladaptive daydreaming (MD) is an immersive fantasy activity that leads to distress and socio-occupational dysfunction. MD has many features suggestive of behavioural addiction, but research exploring the phenomenology of this clinical construct is limited. MD has also been purported to be a maladaptive strategy to cope with distress, but often leads to uncontrollable absorption in fantasy world, social withdrawal and neglected aspects of everyday life. In this paper, we report the case of a 16-year-old boy who developed internet gaming disorder and MD after experiencing cyberbullying from his peers. The patient engaged in vivid, fanciful imagery that lasted for hours, leading to social dysfunction and academic deterioration. Baseline assessment revealed a Maladaptive Daydreaming Scale-16 score of 65 (cut-off 50) and an Internet Gaming Test-20 score of 86 (cut-off 71). The patient was managed primarily with psychological intervention. The therapy focused on behaviour modification and cognitive restructuring. Patients in clinical setting should be questioned about MD when presenting with excessive use of technology or other forms of behavioural addictions. Further studies are necessary to determine the biopsychosocial factors of MD and its correlates. There is also a need to study treatment and management approaches for treating MD.

\section{INTRODUCTION}

Maladaptive daydreaming (MD) is described as 'extensive fantasy activity that replaces human interaction and/or interferes with academic, interpersonal or vocational functioning, ${ }^{1}$ causing clinically significant distress and functional impairment. MD as a construct was first described in six patients who were on treatment for neglect and childhood traumatic events. These patients demonstrated a preference for living in elaborate fantasy worlds and engaging in their inner worlds for more than half of their waking hours, leading to socio-occupational dysfunction. ${ }^{1}$ While some researchers have shown that MD manifests as a coping mechanism for a traumatic event in childhood, others have reported no association with childhood trauma, indicating different aetiological pathways to MD. ${ }^{2}$ Recently, there has been a growing body of research exploring the phenomenology of MD. MD has been viewed from the perspective of behavioural addiction due to its initial rewarding nature, anticipation and intense yearning to repeat the action, and frequent comorbidity with other behavioural addictions such as problematic internet gaming. ${ }^{3} \quad$ Maladaptive daydreamers may share certain similarities with problematic internet gamers, who play games to avoid real-life difficulties (escapism) and use fantasy to experience things that are not workable in real life or live out alternative identities through games. ${ }^{4}$ Internet gaming may involve role-playing games where participants are identified with their characters and co-create imagined scenarios. ${ }^{5}$ Role-playing games, which involve significant imagination, have been associated with the highest risk of generating behavioural addiction. ${ }^{6}$ However, most of the researches have been conducted in a Western setting and there is a paucity of research from the South-East Asian region. We present a case of MD in a young boy, comorbid with internet gaming disorder, who presented to the behaviour addiction clinic of a tertiary hospital in North India.

\section{CASE HISTORY}

\section{Sociodemographic details}

A 16-year-old boy with easy premorbid temperament, studying in senior secondary, belonging to a joint family of upper socioeconomic strata and living in an urban area, presented with excessive use of online gaming accompanied by aggressive behaviour towards family members for the last 1 year. History revealed that the patient had experienced cyberbullying from his schoolmates 2 years ago. His peers circulated his photoshopped 
pictures with obscene content as a joke on him. He felt humiliated and was hesitant to share it with his parents due to the content. After 1 year of continuous bullying, he finally confided in his parents, who in turn informed the school authorities. The bullying stopped when school authorities intervened and informed the parents of the perpetrators. Although he was satisfied with the outcome, he had difficulty in resolving feelings of shame associated with the bullying. From the time of the incident, his academic performance deteriorated and he became withdrawn from his peers, which continued even after the bullying has stopped. However, his mood was not persistently low and his biological functions (sleep, appetite) were not impaired. He managed to pass his examinations and graduated to class 11, where he was introduced to online gaming by one of his friends.

\section{Clinical symptomatology: online gaming addiction}

The patient found online gaming to be a pleasurable pastime and started spending 3-4 hours per day playing online games. He would play the games on his personal computer. He played Fortnite: Save the World, a cooperative shooter-survival game of up to four players to fight off zombie-like creatures and defend objects with fortifications they can build, Fortnite Battle Royale and Fortnite Creative, where players are given complete freedom to create worlds and battle arenas. His usage increased gradually over the next 6 months and he would spend less time with his family and remain restricted to his room. Eventually, he would become verbally aggressive if his gaming devices were taken away. He would stay up whole night to play games and miss his classes the next morning, leading to further deterioration in academics.

While he used to play games with virtual companions, at other times he was completely absorbed in a state of daydreaming, often fantasising about the game in the absence of playing. Intermittently he got flashbacks related to the bullying incident and would resort to listening to music to 'self soothe' and distract himself from those thoughts.

\section{Clinical symptomatology: MD}

In the last 6 months, while listening to music he started to fantasise about the games that he used to play and stay in what he called a 'dream like state'. During this period, he would imagine elaborate scenes inspired by the themes of the online games. The themes of his daydreams were mostly related to him, assuming the identity of the gaming character and an idealised version of himself (owning the characteristics he yearned for), having a lot of friends, having conversations with friends, being powerful and dominant, and taking revenge for the bullying. He would imagine these scenarios in elaborate detail. During 'daydreaming' he would remain completely immersed in the 'fantasy world' and it helped him to calm down and relax. The process of daydreaming was often initiated when the patient listens to music in his leisure time. On other occasions, he would also start daydreaming whenever he had feelings of distress or boredom. He would initially spend 1-2 hours daydreaming, and gradually the duration would increase to 4-6 hours, where he would feel an urge to return to daydreaming as soon as possible when interrupted. The patient would also start daydreaming while in class. During this period, he was also spending 5-6 hours playing internet games. This interfered with his ability to get his basic chores done and he had difficulties in paying attention or sustaining attention in a task without daydreaming. He would often appear inattentive to others while being spoken to, leading to social dysfunction and complaints from his teachers. The vivid fantasies with detailed storylines he imagined while daydreaming served as a distraction from the painful memories related to being bullied. Although the patient was gradually able to perceive that his urge to daydream was interfering with his daily activities, he was unable to control this urge. When daydreaming he perceived a sensation of calmness and comfort, but he would later be distressed thinking about the time wasted over it. Due to the steady academic deterioration and family disturbances, he was brought to the outpatient clinic for management.

\section{Clinical evaluation}

On mental status examination, the patient was wellkempt, conscious, oriented and cooperative for interview. Eye-to-eye contact was made and sustained, and rapport could be established. His affect was euthymic. His attention was aroused but ill-sustained. He did not report any perceptual abnormalities and his higher mental functions were intact. The patient reported about his preoccupation with the bullying incident and feelings of subjective distress related to it. The patient also reported about his daydreaming which he had not previously told his parents. There was no past or family history of psychiatric illness. There was no history suggestive of attention deficit hyperactivity disorder (ADHD) traits in childhood. The patient did not report use of any psychotropic substance. Following detailed assessment an objective evaluation was made using the Maladaptive Daydreaming Scale-16 (MDS-16). ${ }^{7}$ His score on MDS-16 was 65, which was above the cut-off of 50. For gaming use the Internet Gaming Test (IGT-20) ${ }^{8}$ was used, where he scored 86 (cut-off 71).

\section{Diagnostic consideration}

The patient was clinically evaluated for syndromal mood (depression), anxiety (obsessive compulsive disorder (OCD), dissociative disorders), and trauma and stressorrelated disorders (adjustment disorder, post-traumatic stress disorder (PTSD)). However, at the time of evaluation, the patient did not suffer from persistent low mood, recurrent intrusive irrational thoughts or impulses, preoccupation with the stressful event of bullying, flashbacks, nightmares, autonomic arousal and so on. He did not fulfil the criteria for a syndromal mood or anxiety (OCD, PTSD) disorder. The patient demonstrated impaired control over gaming and 'daydreaming', preference for both activities over other life interests and daily activities, 
and continuation of both activities irrespective of significant impairment in socio-occupational functioning. These symptoms have been present over the last 1 year. Because currently only the International Classification of Diseases (ICD-11) accommodates internet gaming disorder as well as other forms of behavioural addiction, the patient was given a comorbid diagnosis of gaming disorder, specifically online (6C51.0), and other specified disorders due to addictive behaviour (6C5Y), as per ICD-11.

\section{Intervention}

Intervention was planned from a psychological viewpoint in three phases: behavioural modification, cognitive restructuring and relapse prevention. The antecedentbehaviour-consequences model was used to identify triggers and associated negative outcomes. The client was taught distraction techniques and 'urge surfing' to replace the maladaptive behaviour with more adaptive coping techniques. Self-soothing strategies such as grounding, mindfulness and deep belly breathing were practised to regulate emotions when experiencing withdrawal in relation to playing games or daydreaming behaviour. Cognitive restructuring was done to address negative self-thoughts associated with the experience of cyberbullying, such as 'I am not worthy', 'I am ashamed' and 'I am unliked'. Good therapeutic alliance enabled positive self-image and increased self-efficacy. Relapse prevention included strategies to cope with urges, identification of triggers (internal-external), seeking company in real life than online, and time used on social media and gaming usage. At the individual level, keeping a diary of occurrence of MD helped to identify activities or stimuli that triggered the onset. Once the underlying causes of escape, avoidance and self-soothing by MD were identified, behavioural interventions for skill-building, such as distraction and relaxation techniques, would help to replace the maladaptive behaviour with adaptive coping responses. The core beliefs of shame and unworthiness established after the bullying incident were dealt with using cognitive-behavioural therapy. There was marked improvement after 12 weeks of therapy (once a week). Post-therapy score on MDS-16 was 46 and on IGT-20 was 62.

\section{DISCUSSION}

The present case demonstrates the phenomenology of MD in a young boy. Until now, only one case of MD (comorbid with chronic schizophrenia) has been reported from the South-East Asian region. ${ }^{9}$ Majority of the literature exploring the clinical phenomenology of MD has been reported in a Western setting. MD is a newly researched entity and is often missed or deemed clinically insignificant in a clinical setting. ${ }^{10}$ Also in the present case, the patient was brought to the outpatient department by his parents primarily for his problematic internet gaming and academic deterioration, and MD was diagnosed only on detailed clinical evaluation. A previous study has reported the presence of high rates of comorbid psychiatric disorders (up to $74.4 \%)^{10}$ associated with $\mathrm{MD}$, the most common being ADHD, OCD, anxiety disorders, and depressive disorders. This could also be the reason for the missed diagnosis as the focus of clinical attention was shifted to the primary psychiatric disorder. Also in the present case, the phenomenon of MD started following and in conjunction with internet gaming disorder. However, it has been reported that treatment for comorbid disorders is not effective for MD and hence warrants a separate focus from a management perspective. $^{11}$

While previous research has adequately highlighted that individuals with a history of traumatic experiences have a higher likelihood of developing problematic internet use ${ }^{12}$ there is also emerging literature on the possible association of childhood trauma and onset of MD. ${ }^{13}$ However, there is a need for further research to explore the aetiopathogenic trajectories of the development of MD, since there are research papers that have also reported MD in individuals who had not suffered from traumatic events in the past. ${ }^{14}$ In those who reported childhood traumatic events, the themes of daydreaming also involved trauma-related imageries and re-enactments. ${ }^{7}$ In the present case as well, the daydreams of the patient included themes related to the cyberbullying he faced. He would re-enact the situations through elaborate fantasies about assuming the identity of the game characters and punishing his bullies.

The present case also demonstrated many of the classic clinical manifestations reported in MD, such as initiation and perpetuation with music, feeling of being in a 'dream-like state', feeling of comfort and calmness during daydreaming, followed by distress over its negative consequences, inability to control the urge to daydream, and feeling of total immersion in the 'fantasy world' while daydreaming.

The phenomenology was distinct from normal daydreaming phenomena, which usually do not last for a long duration and do not cause functional impairment. The urge to daydream, although possessing a compulsive quality, was not perceived as ego-dystonic as in obsessive urges and impulses. The daydreaming was perceived as soothing and pleasurable, but the patient experienced distress regarding its consequences, especially academic decline. Previous research has clearly reported that daydreamers are often distressed about losing control over fantasising and unsuccessful attempts to limit it. ${ }^{14}$ It is also important to distinguish MD from the construct of fantasy proneness, which refers to a habitual engagement in imaginative activities and is viewed as a personality trait associated with high hypnotisability and vivid involvement in mystical and religious experiences. ${ }^{15}$

There is no standard treatment for maladaptive dreaming. However, case formulation provided an insight into the triggers and maintaining factors of gaming and daydreaming, which were the focus of therapy. Psychoeducating the family regarding daydreaming played a 
crucial role in the therapeutic outcome since it provided an opportunity to notice and interrupt MD. Good therapeutic alliance ${ }^{16}$ ensured that the trauma of bullying was talked about in a safe space, and the patient was allowed to reprocess it in a healthier way in the present and thus enhancing his coping strategies for 'acceptance' and 'instrumental support'.

Contributors The case was assessed by PS in OPD. PS wrote the case and further inputs for discussion. Editing was done by AM. Final preparation of draft and proofreading were done by both PS and AM.

Funding The authors have not declared a specific grant for this research from any funding agency in the public, commercial or not-for-profit sectors.

Competing interests None declared.

Patient consent for publication Parental/guardian consent obtained.

Provenance and peer review Not commissioned; externally peer reviewed.

Open access This is an open access article distributed in accordance with the Creative Commons Attribution Non Commercial (CC BY-NC 4.0) license, which permits others to distribute, remix, adapt, build upon this work non-commercially, and license their derivative works on different terms, provided the original work is properly cited, appropriate credit is given, any changes made indicated, and the use is non-commercial. See: http://creativecommons.org/licenses/by-nc/4.0/.

ORCID iD

Prerna Sharma http://orcid.org/0000-0002-9025-5431

\section{REFERENCES}

1 Somer E. Maladaptive daydreaming: a qualitative inquiry. $J$ Contemp Psychother 2002;32:197-212.

2 Bigelsen J, Schupak C. Compulsive fantasy: proposed evidence of an under-reported syndrome through a systematic study of 90 self-identified non-normative fantasizers. Conscious Cogn 2011;20:1634-48.
3 Ballabio M, Griffiths MD, Urbán R. Do gaming motives mediate between psychiatric symptoms and problematic gaming? In: An empirical survey study, addiction research \& theory, 2017: 397-408.

4 Ballabio M, Griffiths MD, Urbán R, et al. Do gaming motives mediate between psychiatric symptoms and problematic gaming? an empirical survey study. Addict Res Theory 2017;25:397-408.

5 Vorobyeva Ol'ga V.. Constructing of group identity during live-action role-playing games. Russ Soc Sci Rev 2016;57:181-93.

6 Lemmens JS, Hendriks SJF. Addictive online games: examining the relationship between game genres and Internet gaming disorder. Cyberpsychol Behav Soc Netw 2016;19:270-6.

7 Somer E, Lehrfeld J, Bigelsen J, et al. Development and validation of the maladaptive Daydreaming scale (MDS). Conscious Cogn 2016;39:77-91.

8 Pontes HM, Király O, Demetrovics Z, et al. The conceptualisation and measurement of DSM-5 Internet gaming disorder: the development of the IGD-20 test. PLoS One 2014;9:e110137.

9 Wang Q, Dong X, Li X. rTMS as an add-on treatment for maladaptive daydreaming over 10 years in patients with schizophrenia: a case report. Asian J Psychiatr 2019;43:208-9.

10 Somer E, Soffer-Dudek N, Ross CA. The comorbidity of Daydreaming disorder (maladaptive Daydreaming). J Nerv Ment Dis 2017;205:525-30.

11 Soffer-Dudek N, Somer E. Trapped in a Daydream: daily elevations in maladaptive Daydreaming are associated with daily psychopathological symptoms. Front Psychiatry 2018;9:194.

12 Dalbudak E, Evren C, Aldemir S, et al. The severity of Internet addiction risk and its relationship with the severity of borderline personality features, childhood traumas, dissociative experiences, depression and anxiety symptoms among Turkish university students. Psychiatry Res 2014;219:577-82.

13 Somer E, Abu-Rayya HM, Brenner R. Childhood trauma and maladaptive daydreaming: fantasy functions and themes in a multicountry sample. J Trauma Dissociation 2020:1-16.

14 Schupak C, Rosenthal J. Excessive daydreaming: a case history and discussion of mind wandering and high fantasy proneness. Conscious Cogn 2009;18:290-2.

15 Wilson SC, Barber TX. The fantasy-prone personality: Implications for understanding imagery, hypnosis, and parapsychological phenomena. In: Sheikh AA, ed. Imagery: current theory, research and application. New York: Wiley, 1983: 340-90.

16 Reynolds C, Simms J, Webb K, et al. Client factors that predict the therapeutic alliance in a chronic, complex trauma sample. Traumatology 2017;23:294-302.

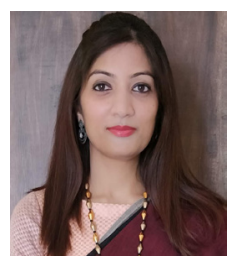

Dr. Prerna Sharma completed her M.Phil. in clinical psychology in 2013 from Government Medical College and Hospital, Chandigarh, India. She subsequently completed her Ph.D. in psychology. She has been currently employed as faculty of clinical psychology at Dr. Ram Manohar Lohia Hospital, New Delhi, since 2018. She currently holds the position of lecturer (clinical psychology) in the Centre of Excellence in Mental Health, Dr. Ram Manohar Lohia Hospital, New Delhi. She is a professional life member of Indian Association of Clinical Psychology (IACP), associate member of Indian Association of Social Psychiatry (IASP) and international affiliate of American Psychological Association. In addition, she started a special clinic for behavioral addictions in Clinical Psychology OPD at RML in 2019. Her main research interests include mindfulness integrated therapies, dialectic behavior therapy, schema work, parenting environment and development of childhood disorders, addictive behaviors and emotional dysregulation. 